\title{
Psychiatric disorders of patients seeking obesity treatment
}

\author{
Hung-Yen Lin ${ }^{1}$, Chih-Kun Huang ${ }^{2}$, Chi-Ming Tai ${ }^{3}$, Hung-Yu Lin ${ }^{4}$, Yu-Hsi Kao ${ }^{5}$, Ching-Chung Tsai ${ }^{6}$, Chin-Feng Hsuan ${ }^{3}$, \\ Su-Long Lee ${ }^{7}$, Shu-Ching Chi ${ }^{8}$ and Yung-Chieh Yen ${ }^{1,9^{*}}$
}

\begin{abstract}
Background: Obese and overweight people have a higher risk of both chronic physical illness and mental illness. Obesity is reported to be positively associated with psychiatric disorders, especially in people who seek obesity treatment. At the same time, obesity treatment may be influenced by psychological factors or personality characteristics. This study aimed to understand the prevalence of mental disorders among ethnic Chinese who sought obesity treatment.

Methods: Subjects were retrospectively recruited from an obesity treatment center in Taiwan. The obesity treatments included bariatric surgery and non-surgery treatment. All subjects underwent a standardized clinical evaluation with two questionnaires and a psychiatric referral when needed. The psychiatric diagnosis was made thorough psychiatric clinic interviews using the SCID. A total of 841 patients were recruited. We compared the difference in psychiatric disorder prevalence between patients with surgical and non-surgical treatment.

Results: Of the 841 patients, $42 \%$ had at least one psychiatric disorder. Mood disorders, anxiety disorders and eating disorders were the most prevalent categories of psychiatric disorders. Females had more mood disorders and eating disorders than males. The surgical group had more binge-eating disorder, adjustment disorder, and sleep disorders than the non-surgical group.
\end{abstract}

Conclusion: A high prevalence of psychiatric disorders was found among ethnic Chinese seeking obesity treatment. This is consistent with study results in the US and Europe.

Keywords: Obesity, Psychiatric disorders, Bariatric surgery

\section{Background}

Obesity is becoming an important issue for health promotion. The World Health Organization estimated that around 1.5 billion adults were overweight (body mass index, BMI $\geqq 25 \mathrm{~kg} / \mathrm{m}^{2}$ ) and about 500 million people were obese $\left(\mathrm{BMI} \geqq 30 \mathrm{~kg} / \mathrm{m}^{2}\right)$ in 2008 . In the United States (US), about $34 \%$ of people are obese [1]. Obese and overweight people have a higher risk of chronic physical illness, such as cardiovascular disease [2], stroke, diabetes mellitus, and hypertension [3]. The relationship between obesity and mental health is also considered important. In a community-based study, obesity was positively associated with several mental disorders, especially mood

\footnotetext{
* Correspondence: jackycyen@yahoo.com

'Department of Psychiatry, E-Da Hospital, Yi-Da Road, Yan-Chau District, Kaohsiung 824, Taiwan

${ }^{9}$ School of Medicine, I-Shou University, Kaohsiung, Taiwan

Full list of author information is available at the end of the article
}

disorders and anxiety disorders [4]. Simon et al. [5] investigated 9125 representative samples in the US, and found that obesity was associated with significant increases in lifetime diagnoses of major depression, bipolar disorder, and panic disorder or agoraphobia. Scott et al. found that even after adjusting for sex and age, obese people still had a higher risk of mood disorder and anxiety disorder [6].

Different obesity treatments including diet control, behavior modification, pharmacotherapy, intra-gastric balloon and bariatric surgery have been used with obesity of different severities. Psychological factors may influence the effect of obesity treatment, no matter whether surgical or non-surgical. Obese people seeking treatment had more psychopathologies, such as anxiety, depression, eating pattern problems, and lower levels of selfesteem and quality of life than normal-weight controls $[7,8]$. Bariatric surgery is effective in weight loss and

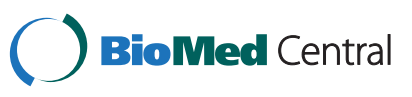


improvement of physical comorbidity in patients with morbid obesity [9]. Before bariatric surgery, a complete pre-operation survey by a multidisciplinary team, including psychological evaluation, is suggested by the $\mathrm{NIH}$ consensus [10].

A substantial proportion of patients receiving bariatric surgery has had psychiatric disorders, including anxiety disorder and mood disorder, throughout their life or even just before surgery $[11,12]$. The role of psychological factors in the outcome of bariatric surgery seems inconsistent. Some studies have found people with psychiatric disorders have less bodyweight loss [13], but others find no relationship or even more bodyweight loss [8]. An emphasis on psychological impact in the postoperative follow-up and detection of possible psychological needs or need of support throughout the treatment course are important [14].

Obesity has become a worldwide public health problem, including Asia. Asian populations have also been shown to have an elevated risk of type 2 diabetes, hypertension, and hyperlipidemia at a relatively low level of BMI, compared to Europeans. Therefore, the criteria for obesity and overweight are lower in Asia [15]. In Taiwan, obesity is defined as BMI $\geqq 27 \mathrm{~kg} / \mathrm{m}^{2}$ by the Department of Health. The estimated prevalence of obesity in Taiwan was $15.9 \%-19.2 \%$ among men and $10.7 \%-16.0 \%$ among women [16-18]. Most obesity studies in Asian countries focus more on the physical effects of obesity and less on mental aspects. In recent years, some studies in Asia have aimed to explore the psychological influence of obesity on community dwellers. Some studies were directed at people in weight reduction treatment, and most of them focused of their quality of life [19-21]. Psychiatric disorders are important in obesity treatment, but there is insufficient evidence on the prevalence of psychiatric disorders in people receiving obesity treatment in Asia.

Hence, we retrospectively evaluated the prevalence of mental disorders in people who sought obesity treatment in Taiwan. We hypothesized that psychiatric disorders were prevalent in obese people, similar to the situation in the US or Europe. We also hypothesized that there might be a difference in psychiatric disorder prevalence between patients undergoing bariatric surgery and those receiving non-surgical treatment.

\section{Methods}

Subjects were recruited from an obesity treatment center in a university hospital in Taiwan. The obesity treatment center personnel comprised a multi-disciplinary team, and included a surgeon, internal physician, psychiatrist, urologist, obstetrics and gynecology doctor, nurse, case manager, dietician, and physical activity director. The obesity treatments in this center included non-surgical procedures: meal replacement, pharmacotherapy, psychiatric bio-feedback treatment and intra-gastric balloon, and surgery: bariatric surgery (sleeve, band, Roux-en-Y gastric bypass). First of all, the patients made up their mind as to the treatment modality. However, the patients who wanted to receive bariatric surgery had to meet the criteria of morbid obesity. They then needed to undergo a complete pre-operation evaluation, including a psychiatric evaluation. Our hospital has a committee in charge of determining whether the patients are eligible for bariatric surgery.

Patients received a complete physical evaluation during their first visit, and also completed two questionnaires: the Taiwanese Depression Questionnaire (TDQ) and the Chinese Health Questionnaire (CHQ). The TDQ is a 0 -3-point, 18-question questionnaire used to screen clinical depressive disorder. [22]. The cut-off point in the community population is $18 / 19$ points. The CHQ [23] is a 12-question, 2-reverse questions, 0-1-point questionnaire for screening "minor psychiatric disorders" such as anxiety disorder. The cut-off point in community surveys screening minor mental disorders is $4 / 5$ points.

To avoid false negative results, we lowered the cut-off points for the CHQ and TDQ in our clinical practice. Those patients with $\mathrm{CHQ}<3$ and TDQ $<13$ were regarded as having no psychiatric disorder. If any of the two scores were above the cut-off point (i.e., $\mathrm{CHQ} \geqq 3$ or TDQ $\geqq 13$, or both), the patients would be referred to psychiatrists for further evaluation. The lifetime psychiatric diagnosis was made based on the psychiatrist's diagnostic interview, using the Structured Clinical Interview for the DSM-IV (SCID).

We recruited all patients that visited the obesity treatment center of E-Da Hospital from January 2007 to December 2010. The exclusion criteria were age younger than 18 years, having incomplete BMI, TDQ or CHQ data, and refusal of psychiatric interview when needed.

All analyses were performed with the Statistical Package for Social Sciences, SPSS Version 17.0. The chi-square test was used to compare differences for categorical variables and the $t$-test was used to compare differences for continuous variables. The level of statistical significances was 0.05 , two-tailed. Logistic regression was applied to examine whether BMI was associated with a psychiatric disorder.

This study was approved by the Institutional Review Board of E-Da Hospital, Taiwan (EMPR-098-073). The study design and performance complied with the Declaration of Helsinki.

\section{Results}

Of the 1832 subjects that were reviewed, the mean BMI was $35.2 \mathrm{~kg} / \mathrm{m}^{2}$ (SD 8.9), 40.2\% received bariatric surgery, $72.1 \%$ were female, and the mean age was 37.6 
years (SD 11.73). Eighty-eight subjects were excluded due to incomplete TDQ and CHQ scores or missing BMI data; 35 were excluded because they were younger than 18 years; 868 were excluded because one of their questionnaire scores was higher than the cut-off point and they refused a further psychiatric interview. We included 841 patients in our analysis (Figure 1). Most of them were female (69.0\%) and their mean age was 35.5 (SD 11.6) years. The mean BMI was 35.7 (SD 8.9) $\mathrm{kg} / \mathrm{m}^{2}$. Of the recruited patients, 455 received bariatric surgery. The surgical group was younger, and had higher BMI, a higher TDQ score, and a higher educational level than the non-surgical group (Table 1).

Psychiatric diagnosis revealed that $42 \%$ of the patients had at least one psychiatric disorder. The 10 most prevalent psychiatric disorders were dysthymic disorder (20.5\%), general anxiety disorder (17.2\%), binge eating disorder (7.6\%), major depressive disorder (7.2\%), adjustment disorder $(2.5 \%)$, sleep disorder $(2.5 \%)$, bulimia nervosa (1.3\%), bipolar disorder (1.2\%), organic mental disorder (1.1\%), and other mood disorders (1,1\%). Mood disorders (27.1\%), anxiety disorders (18.2) and eating disorders $(8.6 \%)$ were the most prevalent categories of psychiatric disorders (Table 2). Women had more mood and eating disorders than men, but there was no sexual difference in anxiety disorders.

Surgical patients were more likely to have "other mood disorder" ( $1.8 \%$ versus $0.3 \%, \mathrm{p}=0.035)$, binge eating

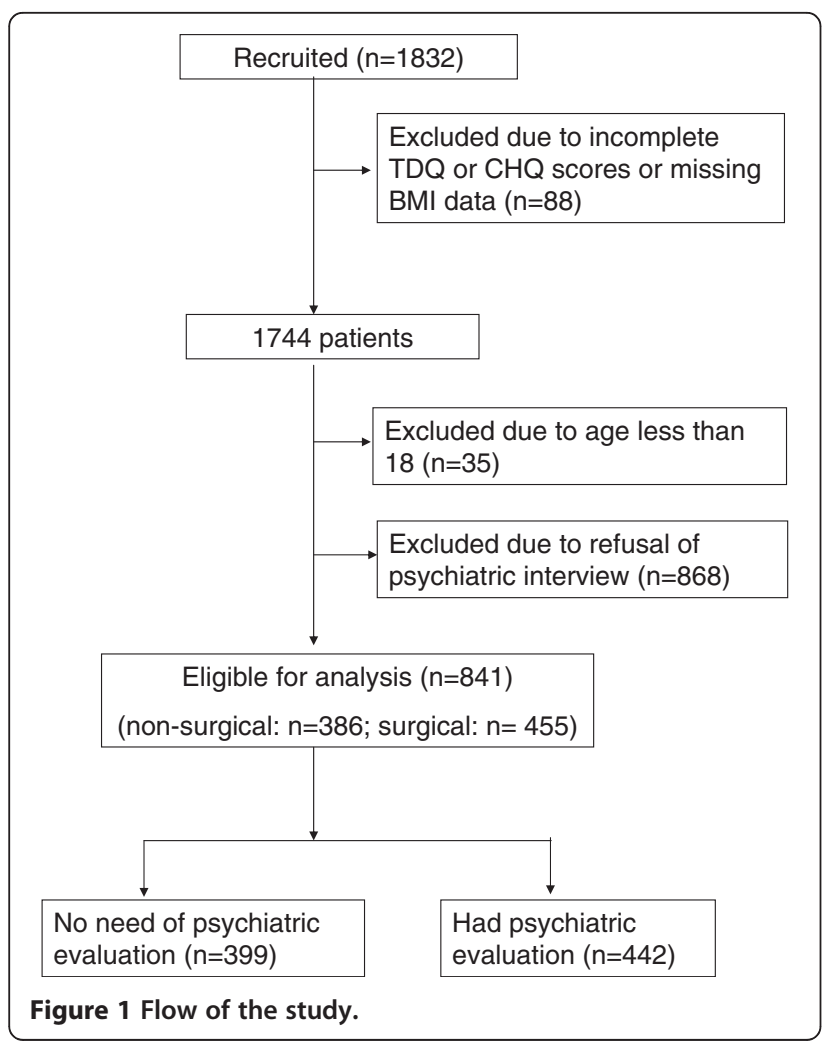

Table 1 Characteristics of patients seeking obesity treatment

\begin{tabular}{|c|c|c|c|}
\hline & Surgical & Non-surgical & $p^{*}$ \\
\hline & $(\mathrm{N}=455)$ & $(\mathrm{N}=386)$ & \\
\hline Female & $321(70.5)$ & $259(67.1)$ & .281 \\
\hline Age (years)(SD) & $34.1(10.8)$ & $37.2(12.4)$ & $<.001$ \\
\hline BMI at First Visit (SD) & $39.5(8.3)$ & $31.2(7.3)$ & $<.001$ \\
\hline \multicolumn{4}{|l|}{ Education, Years (\%) } \\
\hline$>16$ & $23(5.1)$ & $20(4.8)$ & .028 \\
\hline $13-16$ & $234(51.4)$ & $195(51.9)$ & \\
\hline $10-12$ & $154(33.8)$ & $104(27.4)$ & \\
\hline $7-9$ & $26(5.7)$ & $29(7.4)$ & \\
\hline $1-6$ & $17(3.7)$ & $28(7.2)$ & \\
\hline 0 & $1(0.2)$ & $5(1.3)$ & \\
\hline \multicolumn{4}{|l|}{ Marital Status (\%) } \\
\hline single & $257(56.5)$ & $150(39.2)$ & $<.001$ \\
\hline married & $161(35.4)$ & $202(52.7)$ & \\
\hline divorced & $30(6.6)$ & $24(6.3)$ & \\
\hline widowed & $7(1.5)$ & $7(1.8)$ & \\
\hline CHQ score (SD) & $4.2(2.7)$ & $3.8(3.0)$ & .102 \\
\hline TDQ score (SD) & $15.0(11.6)$ & $13.0(13.0)$ & .023 \\
\hline
\end{tabular}

${ }^{*}$ Chi-square test was used for categorical variables; $t$-test was used for continuous variables.

disorder $(10.3 \%$ versus $4.4 \%, \mathrm{p}=0.001)$, adjustment disorder $(3.7 \%$ versus $1.0 \%, \mathrm{p}=0.012)$, and sleep disorders (3.7\% versus $1.0 \%, \mathrm{p}=0.012)$ than non-surgical patients (Table 3). Surgical patients still had a higher prevalence of overall psychiatric disorders, with borderline significance (54.1\% versus $38.6 \%, \mathrm{p}=0.068$ ). In terms of class of psychiatric disorders, surgery patients had more eating disorders than non-surgical patients, but there was no difference in any mood disorder $(27.0 \%$ versus $27.2 \%, \mathrm{p}=0.956)$ and any anxiety disorder $(16.9 \%$ versus $19.7, \mathrm{p}=0.300)$ between the two groups.

We examined whether BMI could predict the presence of psychiatric disorder using logistic regression. Univariate logistic regression showed that BMI could predict the presence of sleep disorder (OR 1.055 [95\% CI 1.011-1.100], $\mathrm{p}=0.013$ ), but that BMI was negatively associated with the presences of any anxiety disorder (OR 0.978 [95\% CI 0.9580.999], $\mathrm{p}=0.004$ ) (Table 4). After adjusting for age, gender, education and marital status, BMI still could predict sleep disorder (OR 1.084 [95\% CI 1.032-1.14], $\mathrm{p}=0.001$ ), and was still negatively associated with the presence of any anxiety disorder (OR 0.975 [95\% CI 0.954-0.997], p=0.027). Female gender was associated with any mood disorder (OR 3.155 [95\% CI 2.094-4.752], $\mathrm{p}<0.001$ ), any eating disorder (OR 3.728 [955 CI 1.734-8.016], $\mathrm{p}=0.001$ ) and any psychiatric disorder (OR 1.779 [95\% CI 1.292-2.448], $\mathrm{p}<0.001$ ), adjusting for BMI, age, marital status, and educational level. 
Table 2 Prevalence of psychiatric disorders by sex

\begin{tabular}{|c|c|c|c|c|}
\hline & \multirow{2}{*}{$\frac{\text { All }}{(\mathrm{N}=841)(\%)}$} & \multicolumn{2}{|c|}{ Male Female } & \multirow[t]{2}{*}{$p^{*}$} \\
\hline & & $(\mathrm{N}=261)(\%)$ & $(\mathrm{N}=580)(\%)$ & \\
\hline Any psychiatric disorder & $353(42.0)$ & $84(32.2)$ & $269(46.4)$ & $<.001$ \\
\hline \multicolumn{5}{|l|}{ Mood disorders } \\
\hline Major depressive disorder & $61(7.3)$ & $6(2.3)$ & $55(9.5)$ & $<.001$ \\
\hline Dysthymic disorder & $173(20.6)$ & $27(10.3)$ & $146(25.2)$ & $<.001$ \\
\hline Depressive disorder, NOS & $3(0.4)$ & $1(0.4)$ & $2(0.3)$ & .931 \\
\hline Bipolar disorder & $10(1.2)$ & $3(1.1)$ & $7(1.2)$ & .943 \\
\hline Other mood disorder & $9(1.1)$ & $1(0.4)$ & $8(1.4)$ & .194 \\
\hline Any mood disorder & $228(27.1)$ & $34(13.0)$ & $194(33.4)$ & $<.001$ \\
\hline \multicolumn{5}{|l|}{ Anxiety disorder } \\
\hline General anxiety disorder & $145(17.2)$ & $45(17.2)$ & $100(17.2)$ & $>.999$ \\
\hline OCD & $1(0.1)$ & $1(0.4)$ & $0(0)$ & .136 \\
\hline Panic disorder & $6(0.7)$ & $2(0.8)$ & $4(0.7)$ & .903 \\
\hline PTSD & $3(0.4)$ & $1(0.4)$ & $2(0.3)$ & .931 \\
\hline Specific phobia & $1(0.1)$ & $0(0)$ & $1(0.2)$ & .502 \\
\hline Social phobia & $1(0.1)$ & $0(0)$ & $1(0.2)$ & .502 \\
\hline Anxiety disorder, NOS & $3(0.4)$ & $2(0.8)$ & $1(0.2)$ & .181 \\
\hline Any anxiety disorder & $153(18.2)$ & $47(18.0)$ & $106(18.3)$ & .926 \\
\hline Adjustment disorder & $21(2.5)$ & $7(2.7)$ & $14(2.4)$ & .818 \\
\hline \multicolumn{5}{|l|}{ Eating disorders } \\
\hline Bulimia nervosa & $11(1.3)$ & $2(0.8)$ & $9(1.6)$ & .354 \\
\hline Anorexia nervosa & $2(0.2)$ & $0(0)$ & $2(0.3)$ & .342 \\
\hline Binge eating disorder & $64(7.6)$ & $7(2.7)$ & $57(9.8)$ & $<.001$ \\
\hline Any eating disorder & $72(8.6)$ & $8(3.1)$ & $64(11.0)$ & $<.001$ \\
\hline \multicolumn{5}{|l|}{ Psychotic disorders } \\
\hline Schizophrenia & $7(0.8)$ & $1(0.4)$ & $6(1.0)$ & .336 \\
\hline Other psychotic disorder & $3(0.4)$ & $1(0.4)$ & $2(0.3)$ & .931 \\
\hline \multicolumn{5}{|l|}{ Substance use disorders } \\
\hline Alcohol-related disorders & $5(0.6)$ & $1(0.4)$ & $4(0.7)$ & .593 \\
\hline Other substance-related disorder except for nicotine & $0(0)$ & $0(0)$ & $0(0)$ & \\
\hline Organic mental disorders & $9(1.1)$ & $3(1.1)$ & $6(1 / 0)$ & .881 \\
\hline Personality disorders & $3(0.4)$ & $0(0)$ & $3(0.5)$ & .224 \\
\hline Sleep disorders & $21(2.5)$ & $11(4.2)$ & $10(1.7)$ & .032 \\
\hline
\end{tabular}

${ }^{*}$ Chi-square test was used to compare differences in prevalence between males and females.

\section{Discussion}

This is, to our knowledge, the first paper in Asia to explore the prevalence of psychiatric disorders in Asian patients who seek obesity treatment. We retrospectively reviewed 841 patients who received different obesity treatments, including non-surgical procedures and bariatric surgery. The patients underwent a standardized clinical evaluation using two questionnaires, and psychiatric referral when needed. Clinical evaluation revealed that $42 \%$ of patients had at least one psychiatric disorder. Mood disorders and anxiety disorders were the most prevalent.
Kalarchian et al. [11] evaluated 288 bariatric surgery candidates. They found high prevalence rates of lifetime psychiatric disorders $(66.3 \%)$ in these patients, even before surgery; $37.8 \%$ of patients had at least one psychiatric disorder. Rosenburger et al. [24] in the US and Muhlhans et al. [12] in Germany also found that patients had a high prevalence of psychiatric disorders before bariatric surgery (36.8\%, and $72.6 \%$, respectively). Our prevalence of any psychiatric disorder (54.1\%) in the surgical group was lower than that of Kalarchian and Muhlhans, but higher than that of Rosenberger. Of all our patients receiving 
Table 3 Prevalence of psychiatric disorders by intervention modalities

\begin{tabular}{|c|c|c|c|}
\hline & Surgical & Non- surgical & $p^{*}$ \\
\hline & $(\mathrm{N}=455)(\%)$ & $(\mathrm{N}=386)(\%)$ & \\
\hline Any psychiatric disorder & $204(54.1)$ & $149(38.6)$ & .068 \\
\hline \multicolumn{4}{|l|}{ Mood disorders } \\
\hline Major depressive disorder & $31(6.8)$ & $30(7.8)$ & .593 \\
\hline Dysthymic disorder & $97(21.3)$ & $76(19.7)$ & .560 \\
\hline Depressive disorder, NOS & $3(0.7)$ & 0 & .110 \\
\hline Bipolar disorder & $6(1.3)$ & $4(1.0)$ & .707 \\
\hline Other mood disorder & $8(1.8)$ & $1(0.3)$ & .035 \\
\hline Any mood disorder & $123(27.0)$ & $105(27.2)$ & .956 \\
\hline \multicolumn{4}{|l|}{ Anxiety disorders } \\
\hline General anxiety disorder & $72(15.8)$ & $73(18.9)$ & .237 \\
\hline Obsessive-compulsive disorder & 0 & $1(0.3)$ & .277 \\
\hline Panic disorder & $1(0.1)$ & $5(0.6)$ & .065 \\
\hline Post-traumatic stress disorder & 0 & $3(0.8)$ & .060 \\
\hline Specific phobia & $1(0.2)$ & 0 & .357 \\
\hline Social phobia & $1(0.2$ & 0 & .357 \\
\hline Anxiety disorder, NOS & $3(0.7)$ & 0 & .110 \\
\hline Any anxiety disorder & $77(16.9)$ & $76(19.7)$ & .300 \\
\hline Adjustment disorders & $17(3.7)$ & $4(1.0)$ & .012 \\
\hline \multicolumn{4}{|l|}{ Eating disorders } \\
\hline Bulimia nervosa & $5(1.1)$ & $6(1.6)$ & .562 \\
\hline Anorexia nervosa & 0 & $2(0.2)$ & .127 \\
\hline Binge eating disorder & $47(10.3)$ & $17(4.4)$ & .001 \\
\hline Any eating disorder & $49(10.8)$ & $23(6.0)$ & .013 \\
\hline \multicolumn{4}{|l|}{ Psychotic disorders } \\
\hline Schizophrenia & $3(0.7)$ & $4(1.0)$ & .549 \\
\hline Other psychotic disorder & $3(0.3)$ & 0 & .110 \\
\hline Alcohol-related disorders & $2(0.4)$ & $3(0.8)$ & .526 \\
\hline Organic mental disorders & $4(0.9)$ & $5(1.3)$ & .559 \\
\hline Personality disorders & 0 & $3(0.3)$ & .060 \\
\hline Sleep disorders & $17(3.7)$ & $4(1.0)$ & .012 \\
\hline
\end{tabular}

surgical or non-surgical treatment, the prevalence of any psychiatric disorder was $42 \%$. This is not so different from the findings among Caucasians. We also found that mood disorders and anxiety disorders were the most prevalent classes of disorders, similar to the other studies. Eating disorders were the third most prevalent. We had a low frequency of substance abuse disorders $(0.6 \%)$, and some patients had adjustment disorder and sleep disorders, which were not mentioned in the other three studies.

The differences in findings between our study and the other studies may be due to race, social factors and different study designs. The evaluation tool in the above three studies in the US and Germany was the structured interview, performed by well-trained psychologists. In our study, all psychiatric diagnoses were confirmed by board-certified psychiatrists. Our psychiatric evaluation is a part of the standardized pre-treatment evaluation process. However, patients might be worried about disclosing psychiatric problems if they thought it would affect their treatment, which may have lowered the prevalence of psychiatric disorders, as Muhlhans et al. [12] mentioned.

In our study, about $70 \%$ of patients were female. Females had a higher prevalence of mood disorders and eating disorders than males, but the males had more sleep disorders. There was no difference in anxiety disorder between the men and women. Similar outcomes were noted in our logistic regression models in Table 4. A previous community-based study, an international study in 13 areas worldwide involving 62,277 cases from the World Mental Health Survey [25], found that obesity increased the odds ratio of depression and anxiety, especially in females. The possible mechanism may be that women have more psychological stress from the stigma of obesity, greater dissatisfaction with their body image, and more eating problems [26].

Our finding is similar to that of Muhlhans' study [12], in which women had more prevalent psychiatric disorders than men, but inconsistent with that of Kalarchian's study. In Asia, the criteria for obesity are lower than in Europe and the US, which means that people are generally thinner in Asia. No matter whether physical or socio-cultural factors are involved, women in Asia whose $\mathrm{BMI}$ is the same as that of men may have more psychological stress when dealing with obesity. In our study, patients in the surgical group were younger and had higher BMI than those in the non-surgical group. Eating disorders, especially binge eating disorder, is prevalent in bariatric surgery patients [11] and has affected the outcome of weight loss after surgery [27,28]. Postoperative binge eating disorder can predict a poor surgical outcome. However, in our study, there were no differences between the two groups in terms of the prevalence of the other two important psychiatric disorders: mood and anxiety disorders. These two disorders may be affected by many different and complex psychosocial factors, not only BMI. Patients in the surgical group had a higher prevalence of several specific psychiatric disorders (adjustment disorder, binge eating disorder, and sleep disorders) than their non-surgical counterparts, but overall, psychiatric disorders were prevalent in both groups. This implies that people who seek obesity treatment, no matter the treatment they receive, suffer from similar psychopathological processes, with some exceptions.

The mood disorders, including bipolar disorder and depressive disorder, were the most prevalent class of disorders 
Table 4 BMI predicting the presence of psychiatric disorders using logistic regression

\begin{tabular}{|c|c|c|c|c|}
\hline & OR $(95 \% \mathrm{Cl})^{*}$ & $p$ & $\begin{array}{l}\text { Adjusted OR } \\
(95 \% \mathrm{Cl})\end{array}$ & $p$ \\
\hline \multicolumn{5}{|l|}{ Any mood disorder } \\
\hline BMI & $0.993(0.976-1.010)$ & 0.425 & 0.999 (0.980-1.018) & 0.890 \\
\hline Female & & & 3.155 (2.094-4.752) & $<0.001$ \\
\hline Age (years) & & & $0.988(9.68-1.008)$ & 0.226 \\
\hline \multicolumn{5}{|l|}{ Marital status } \\
\hline \multicolumn{5}{|l|}{ single } \\
\hline married & & & $1.188(0.765-1.846)$ & 0.443 \\
\hline divorced or widowed & & & $2.808(1.508-5.230)$ & 0.001 \\
\hline \multicolumn{5}{|l|}{ Any anxiety disorder } \\
\hline BMl & $0.978(0.958-0.999)$ & 0.04 & $0.975(0.954-0.997)$ & 0.027 \\
\hline Female & & & $0.920(0.619-1.385)$ & 0.697 \\
\hline Age (years) & & & $0.995(0.973-1.018)$ & 0.680 \\
\hline \multicolumn{5}{|l|}{ Marital status } \\
\hline \multicolumn{5}{|l|}{ single } \\
\hline married & & & $0.853(0.519-14.03)$ & 0.531 \\
\hline divorced or widowed & & & $0.871(0.408-1.860)$ & 0.722 \\
\hline \multicolumn{5}{|l|}{ Any eating disorder } \\
\hline BMI & $1.015(0.988-1.042)$ & 0.280 & $1.008(0.980-1.038)$ & 0.573 \\
\hline Female & & & 3.728 (1.734-8.016) & 0.001 \\
\hline Age (years) & & & $0.973(0.940-1.007)$ & 0.114 \\
\hline \multicolumn{5}{|l|}{ Marital status } \\
\hline \multicolumn{5}{|l|}{ single } \\
\hline married & & & $0.608(0.0293-1.264)$ & 0.183 \\
\hline divorced or widowed & & & $1.152(0.434-3.055)$ & 0.776 \\
\hline \multicolumn{5}{|l|}{ Sleep disorders } \\
\hline BMI & $1.055(1.011-1.100)$ & 0.013 & $1.084(1.032-1.140)$ & 0.001 \\
\hline Female & & & $0.629(0.247-1.599)$ & 0.330 \\
\hline Age (years) & & & $1.013(0.957-1.072)$ & 0.658 \\
\hline \multicolumn{5}{|l|}{ Marital status } \\
\hline \multicolumn{5}{|l|}{ single } \\
\hline married & & & $4.653(1.299-16.670)$ & 0.018 \\
\hline divorced or widowed & & & $1,676(0.168-16.68)$ & 0.659 \\
\hline \multicolumn{5}{|l|}{ Any psychiatric disorder } \\
\hline BMI & $1.003(0.988-1.019)$ & 0.6761 .004 & $(0.987-10.02)$ & 1.004 \\
\hline Female & 1.779 & & $(1.292-2.448)$ & $<0.001$ \\
\hline Age (years) & & & $0.982(0.965-1.000)$ & 0.050 \\
\hline \multicolumn{5}{|l|}{ Marital status } \\
\hline \multicolumn{5}{|l|}{ single } \\
\hline married & & & $1.209(0.818-1.788)$ & 0.340 \\
\hline divorced or widowed & & & $2.152(1.186-3.906)$ & 0.012 \\
\hline
\end{tabular}

*OR, odds ratio; $\mathrm{Cl}$, confidence interval.

Note. Educational level was also adjusted but not shown here. None of each educational level was predictive of the presence of psychiatric disorders. 
in our study. Patients with bipolar disorder are at a higher risk of being overweight and obese. The possible risk factors for weight gain in bipolar disorder patients include comorbid binge-eating disorder; the number of depressive episodes, treatment with medications associated with weight gain, low rates of exercise [29], age, comorbid anxiety disorders, duration of depressive episodes, and history of hospitalization for depression [30]. The interventions used with obese bipolar patients should include better metabolite profile medication, adjunctive pharmacotherapy for weight loss, and the integration of lifestyle factors and weight-management counseling in the long-term care plan $[30,31]$. Depression may lower the patient's level of energy and motivation, or change their appetite, making them less careful about their health. The relationship between depression and obesity is bi-directional, as seen in the metaanalytical evidence. Researchers found that obese persons had a 55\% increased risk of developing depression over time, whereas depressed persons had a 58\% increased risk of becoming obese (26). The possible etiology of the association between obesity and depression may be biological and psychological, but this requires further evaluation.

In this study, we found that higher BMI was associated with sleep disorders. Sleep disturbance in obese people may be related to anatomical factors, endocrinological factors, and metabolic circadian abnormalities of the physical condition [32]. About 70\% of people with obstructive sleep apnea are obese. On the other hand, the prevalence of sleep apnea disorder among obese people is approximately $40 \%$ [33]. In previous research, attention deficit hyperactivity disorder (ADHD) was reported to be associated with obesity, binge eating behavior and sleep/alertness problems [34]. Cortese et al. proposed that obesity might be one of the factors associated with the sleep/alertness problem and manifest as ADHD-like symptoms. The association of obesity with ADHD is a novel area in need of attention and further study.

Our study had an adequate sample size (841 subjects, including 455 surgical patients and 368 non-surgical patients). We compared the characteristics and clinical correlates of psychiatric disorders in obese patients. Few studies have explored the differences before. The psychia tric disorders in this study were diagnosed by boardcertified psychiatrists and hence had good reliability. However, some limitations of our study should be noted. The high rates of refusal of psychiatric evaluation may affect our results. One of the explanations may be that people in Taiwan do not understand that obesity is not only a physical disease, but also a possible mental disorder. They may worry about the stigma and are unwilling to visit a psychiatrist. All patients in our study were recruited from one university hospital. The community hospitals in Taiwan do not provide bariatric surgery, though some community hospitals treat obese people with non-surgical interventions. No known demographic difference between patients in community hospitals and university hospitals has ever been reported.

In recent years, many studies have focused not only on pre-treatment psychiatric problems, but also on posttreatment follow-up. Obesity treatment, including bariatric surgery, is still under development in Asia, and psychiatric involvement is imperative for a comprehensive treatment. Future studies should focus on the effects of ethnicity and culture, which are diverse in Asian countries.

\section{Conclusions}

A high prevalence of psychiatric disorders was found among ethnic Chinese seeking obesity treatment. Mood disorders, anxiety disorders and eating disorders were the most prevalent categories of psychiatric disorders. The surgical group had more binge-eating disorders, other mood disorders, adjustment disorder, and sleep disorders than the non-surgical group. Psychiatric evaluation might be an important factor in complete obesity treatment and require further study.

\section{Competing interests}

The authors declare no competing interests.

\section{Authors' contributions}

$\mathrm{LH}-\mathrm{Y}$ and $\mathrm{YY}-\mathrm{C}$ were responsible for the study design, data collection, and manuscript writing. HC-K, TC-M and LH-Y recruited participants and collected data. TC-C and HC-F analyzed data. KY-H, LS-L and CS-C helped analyze data and prepare the manuscript. All authors read and approved the final manuscript.

\section{Acknowledgement}

This study was supported by a grant from E-Da Hospital, Taiwan (EDAH99013).

\section{Author details}

'Department of Psychiatry, E-Da Hospital, Yi-Da Road, Yan-Chau District, Kaohsiung 824, Taiwan. ${ }^{2}$ Bariatric \& Metabolic International Surgery Center, E-Da Hospital, Kaohsiung, Taiwan. ${ }^{3}$ Department of Internal Medicine, E-Da Hospital, Kaohsiung, Taiwan. ${ }^{4}$ Department of Urology, E-Da Hospital, Kaohsiung, Taiwan. ${ }^{5}$ Department of Endocrinology and Metabolism, E-Da Hospital , Kaohsiung, Taiwan. 'Department of Pediatrics, E-Da Hospital, Kaohsiung, Taiwan. ${ }^{7}$ Department of Obstetrics and Gynecology, E-Da Hospital, Kaohsiung, Taiwan. ${ }^{8}$ Nursing Department, E-Da Hospital, I-Shou University, Kaohsiung, Taiwan. ${ }^{9}$ School of Medicine, I-Shou University, Kaohsiung, Taiwan.

Received: 14 May 2012 Accepted: 27 December 2012 Published: 2 January 2013

\section{References}

1. Flegal KM, Carroll MD, Ogden CL, Curtin LR: Prevalence and trends in obesity among US adults, 1999-2008. JAMA 2010, 303:235-241.

2. Ebbeling CB, Pawlak DB, Ludwig DS: Childhood obesity: public-health crisis, common sense cure. Lancet 2002, 360:473-482.

3. Must A, Spadano J, Coakley EH, Field AE, Colditz G, Dietz WH: The disease burden associated with overweight and obesity. JAMA 1999, 282:1523-1529.

4. Stunkard AJ, Faith MS, Allison KC: Depression and obesity. Biol Psychiatry 2003, 54:330-337.

5. Simon GE, Von Korff M, Saunders K, Miglioretti DL, Crane PK, van Belle G, Kessler RC: Association between obesity and psychiatric disorders in the US adult population. Arch Gen Psychiatry 2006, 63:824-830. 
6. Scott KM, McGee MA, Wells JE, Oakley Browne MA: Obesity and mental disorders in the adult general population. J Psychosom Res 2008, 64:97-105.

7. Abiles V, Rodriguez-Ruiz S, Abiles J, Mellado C, Garcia A, Perez de la Cruz A Fernandez-Santaella MC: Psychological characteristics of morbidly obese candidates for bariatric surgery. Obes Surg 2010, 20:161-167.

8. Averbukh Y, Heshka S, El-Shoreya H, Flancbaum L, Geliebter A, Kamel S, Pi-Sunyer FX, Laferrere B: Depression score predicts weight loss following roux-en-Y gastric bypass. Obes Surg 2003, 13:833-836.

9. Buchwald $H$, Avidor $Y$, Braunwald $E$, Jensen MD, Pories W, Fahrbach $K$, Schoelles K: Bariatric surgery: a systematic review and meta-analysis. JAMA 2004, 292:1724-1737.

10. NIH conference: Gastrointestinal surgery for severe obesity. Consensus development conference panel. Ann Intern Med 1991, 115:956-961.

11. Kalarchian MA, Marcus MD, Levine MD, Courcoulas AP, Pilkonis PA, Ringham RM, Soulakova JN, Weissfeld LA, Rofey DL: Psychiatric disorders among bariatric surgery candidates: relationship to obesity and functional health status. Am J Psychiatry 2007, 164:328-334. quiz 374.

12. Muhlhans B, Horbach T, de Zwaan M: Psychiatric disorders in bariatric surgery candidates: a review of the literature and results of a German prebariatric surgery sample. Gen Hosp Psychiatry 2009, 31:414-421.

13. Kinzl JF, Schrattenecker M, Traweger C, Mattesich M, Fiala M, Biebl W: Psychosocial predictors of weight loss after bariatric surgery. Obes Surg 2006, 16:1609-1614.

14. Pull CB: Current psychological assessment practices in obesity surgery programs: what to assess and why. Curr Opin Psychiatry 2010, 23:30-36.

15. WHO expert consultation: Appropriate body-mass index for Asian populations and its implications for policy and intervention strategies. Lancet 2004, 363:157-163.

16. Shimokawa S, Chang HH, Pinstrup-Andersen P: Understanding the differences in obesity among working adults between Taiwan and china. Asia Pac J Clin Nutr 2009, 18:88-95.

17. Chu NF: Prevalence of obesity in Taiwan. Obes Rev 2005, 6:271-274.

18. Hwang LC, Bai CH, Chen CJ: Prevalence of obesity and metabolic syndrome in Taiwan. J Formos Med Assoc 2006, 105:626-635.

19. Chang CY, Hung CK, Chang YY, Tai CM, Lin JT, Wang JD: Health-related quality of life in adult patients with morbid obesity coming for bariatric surgery. Obes Surg 2010, 20:1121-1127.

20. Loh CB, Chan YH: Psychological symptoms in people presenting for weight management. Ann Acad Med Singapore 2010, 39:778-782.

21. Kim JY, Oh DJ, Yoon TY, Choi JM, Choe BK: The impacts of obesity on psychological well-being: a cross-sectional study about depressive mood and quality of life. J Prev Med Public Health 2007, 40:191-195.

22. Lee Y, Yang MJ, Lai TJ, Chiu NM, Chau TT: Development of the Taiwanese depression questionnaire. Chang Gung Med J 2000, 23:688-694.

23. Cheng TA, Williams $P$ : The design and development of a screening questionnaire (CHQ) for use in community studies of mental disorders in Taiwan. Psychol Med 1986, 16:415-422.

24. Rosenberger PH, Henderson KE, Grilo CM: Psychiatric disorder comorbidity and association with eating disorders in bariatric surgery patients: a cross-sectional study using structured interview-based diagnosis. J Clin Psychiatry 2006, 67:1080-1085.

25. Scott KM, Bruffaerts R, Simon GE, Alonso J, Angermeyer M, de Girolamo G, Demyttenaere K, Gasquet I, Haro JM, Karam E, et al: Obesity and mental disorders in the general population: results from the world mental health surveys. Int J Obes (Lond) 2008, 32:192-200.

26. Striegel-Moore $\mathrm{RH}$, Silberstein $L R$, Rodin J: Toward an understanding of risk factors for bulimia. Am Psychol 1986, 41:246-263.

27. Busetto L, Segato G, De Luca M, De Marchi F, Foletto M, Vianello M, Valeri M, Favretti F, Enzi G: Weight loss and postoperative complications in morbidly obese patients with binge eating disorder treated by laparoscopic adjustable gastric banding. Obes Surg 2005, 15:195-201.

28. Scholtz S, Bidlake L, Morgan J, Fiennes A, El-Etar A, Lacey JH, McCluskey S: Long-term outcomes following laparoscopic adjustable gastric banding: postoperative psychological sequelae predict outcome at 5-year follow-up. Obes Surg 2007, 17:1220-1225.

29. Keck PE, McElroy SL: Bipolar disorder, obesity, and pharmacotherapyassociated weight gain. J Clin Psychiatry 2003, 64:1426-1435.

30. Goldstein BI, Liu SM, Zivkovic N, Schaffer A, Chien LC, Blanco C: The burden of obesity among adults with bipolar disorder in the united states. Bipolar Disord 2011, 13:387-395.
31. McElroy SL, Keck PE Jr: Obesity in bipolar disorder: an overview. Curr Psychiatry Rep 2012, 14:650-658.

32. Akinnusi ME, Saliba R, Porhomayon J, El-Solh AA: Sleep disorders in morbid obesity. Eur J Intern Med 2012, 23:219-226.

33. Resta O, Foschino-Barbaro MP, Legari G, Talamo S, Bonfitto P, Palumbo A, Minenna A, Giorgino R, De Pergola G: Sleep-related breathing disorders, loud snoring and excessive daytime sleepiness in obese subjects. Int J Obes Relat Metab Disord 2001, 25:669-675.

34. Cortese S, Morcillo Penalver C: Comorbidity between ADHD and obesity: exploring shared mechanisms and clinical implications. Postgrad Med 2010, 122:88-96.

doi:10.1186/1471-244X-13-1

Cite this article as: Lin et al:: Psychiatric disorders of patients seeking obesity treatment. BMC Psychiatry 2013 13:1.

\section{Submit your next manuscript to BioMed Central and take full advantage of:}

- Convenient online submission

- Thorough peer review

- No space constraints or color figure charges

- Immediate publication on acceptance

- Inclusion in PubMed, CAS, Scopus and Google Scholar

- Research which is freely available for redistribution

Submit your manuscript at www.biomedcentral.com/submit
C Biomed Central 